\title{
As licenciaturas na atualidade: nova crise?
}

\section{Teacher training courses in the present time: new crisis?}

\author{
Antônia Vitória Soares Aranha ${ }^{1}$ \\ João Valdir Alves de Souza ${ }^{1}$
}

\begin{abstract}
RESUMO
Este artigo visa situar o debate atual sobre a crise nas licenciaturas, pontuando algumas circunstâncias históricas tanto de afirmação e ampliação da escola como locus privilegiado do ensino no mundo moderno quanto da emergência do sentimento de que ela não cumpriu a promessa de formar cidadãos autônomos, livres e iguais em direitos. Exemplifica essa crise com dados apurados pela Pró-Reitoria de Graduação (PROGRAD) e pelo Colegiado Especial de Licenciaturas da Universidade Federal Minas Gerais (UFMG) sobre a relação candidato/vaga nos seus últimos 15 vestibulares. Esses dados apontam para um contínuo esvaziamento dos cursos de licenciatura, tanto no que se refere aos vestibulares quanto aos que se formam, mas optam por ocupações mais vantajosas economicamente. Isso traz questões relevantes para se pensar tanto a formação inicial quanto a formação continuada de professores, uma vez que, em decorrência das vertiginosas mudanças na vida social contemporânea, há um descompasso entre os processos de formação e a emergência de novas demandas para as quais o corpo docente parece sempre estar despreparado para assumir.

Palavras-chave: licenciaturas; formação de professores; condição docente; crise na educação; licenciaturas na UFMG.
\end{abstract}

\footnotetext{
ABSTRACT

The article focuses on the current debate on the crisis of teacher education, pointing out some historic circumstances of either affirmation and amplification of school as the privileged place for teaching in the modern world,

1 Universidade Federal de Minas Gerais. Belo Horizonte, Minas Gerais, Brasil. Av. Antônio Carlos, Nº 6627 - Pampulha. CEP: 31.270-901.
} 
and also the emergence of the feeling that it did not accomplish the promise of developing autonomous citizens, free and equal in rights. We exemplify this crisis using data from PROGRAD and from the UFMG's "special staff group for teaching education" on the relation between candidate numbers and available places during its last 15 years of exams for university entrance. These data shows a continuous emptying of the teacher education undergraduate courses, referring both to entering the university and to graduating but choosing other more economically profitable jobs. This brings out relevant points to think about both the beginning and the continuous education process of teachers since, as a consequence of changes in social contemporary life, there is a mismatch between the processes of training and the emergence of new demands for which the education staff seems not always to be prepared to assume.

Keywords: teacher education; teacher training; teaching staff; education crisis; UFMG teacher education.

\section{Introdução}

Tornou-se um lugar-comum afirmar que os cursos de licenciatura vivem atualmente uma profunda crise. Porém, como afirma Sérgio Paulo Rouanet (1993), ao escrever sobre a crise da modernidade, "como outros lugares-comuns este pode até ser verdadeiro, desde que se entenda bem o alcance do diagnóstico" (ROUANET, 1993, p. 9). A tese de Rouanet é que a crise da modernidade é uma crise de civilização.

O que está em crise é o projeto moderno de civilização, elaborado pela Ilustração européia a partir de motivos da cultura judeo-clássica-cristã e aprofundado nos dois séculos subseqüentes por movimentos como o liberal-capitalismo e o socialismo." (ROUANET, 1993, p. 9).

Se tomarmos como consistente essa tese de Rouanet (1993) e entendermos que a forma escolar predominante nos nossos dias se constituiu como parte fundamental desse projeto moderno de civilização, o argumento básico do diagnóstico passa pelo entendimento de que a formação de professores está em crise porque está em crise a escola constituída como parte desse projeto. Em outras palavras, o que está em crise é o próprio sistema de ensino moderno, 
constituído no contexto dos modernos estados nacionais a partir do século XIX. Como essa generalidade pode nos levar ao extremo de dizer, como foi dito por um experiente biólogo em assembleia de professores em greve, que "desde quando descemos das árvores estamos em crise", é preciso trazer elementos mais palpáveis ao diagnóstico para que ele tenha algum poder de explicação da situação atual.

O propósito deste artigo é trazer elementos para ampliar nossa compreensão de um paradoxo: quanto mais falamos em crise da educação escolar, mais escolarizada se torna a nossa sociedade; e quanto mais vemos entrar na escola os públicos que por ela lutaram, ao longo desses dois últimos séculos, maior é a nossa sensação de que a educação escolar está em crise. Qualquer tentativa de entendimento da questão deve começar, então, necessariamente pelo entendimento do significado da palavra "crise". A partir desse entendimento, tentaremos especificar algumas características atuais do nosso sistema de ensino e apontar alguns elementos constitutivos da atual crise dos cursos de licenciatura.

\section{A crise}

Conforme pode ser lido em vários dicionários (CUNHA, 2010; HOUAISS, 2001; FERREIRA, 1986; BRUNKHOST, 1996), a palavra “crise" vem do latim crisis, que por sua vez deriva do grego krísis, que também está na origem da palavra "crítica". O entendimento mais comum permitido por esses dicionários é o de que a crise expressa a alteração ou desequilíbrio repentino (CUNHA, 2010, p. 190), o que submete determinada realidade a um estado de dúvida e incerteza, com extensa designação de situações que vão dos organismos vivos às estruturas socioeconômicas. Esse desequilíbrio pode ser conjuntural, se ele afeta em escala menor e em tempo relativamente curto a situação observada, ou estrutural, se ele afeta a própria estrutura constitutiva dessa realidade e se prolonga no tempo. A crise de que tratamos, portanto, pode ser caracterizada como estrutural e parece ter nascido com a própria constituição dos sistemas de ensino.

Mas a crise pode ser entendida, também, como a "ação ou faculdade de distinguir, ação de escolher, decidir, julgar” (HOUAISS, 2001, p. 872). É por essa perspectiva que podemos entender a crise como uma relação. Essa relação pode ser observada tanto em face de dados objetivos tomados como referência (percentual de crescimento econômico menor agora que em períodos anteriores ou em comparação com outra unidade de análise) quanto em face da nossa capa- 
cidade de fazer escolhas, tomar decisões e fazer julgamentos. Quanto mais amplo é o espectro das escolhas maior é a possibilidade de que se instaure a dúvida e, com ela, a sensação de desconforto, instabilidade e desequilíbrio. Quanto mais ampla for a nossa capacidade de fazer julgamentos, maior é a probabilidade de encontrarmos uma realidade não correspondente aos nossos desejos, sejam os de ordem mais íntima e particular, sejam aqueles que brotaram de grandes projetos coletivos e da vida pública. Sob essa perspectiva, a crise é a não realização do projeto ou da promessa e ela é tão mais amplamente sentida quanto maior é a expectativa gerada por essa promessa e a nossa capacidade de julgá-la.

Todo projeto traz, de certa forma, uma promessa. Mesmo que a palavra "promessa" tenha ficado cada vez mais circunscrita ao campo religioso (promissa, promissão) e "projeto" expresse sua variação secular, racionalizada e submetida ao cálculo da relação entre meios e fins, nada nos impede de ver como promissora uma ideia que encontra campo fértil para sua efetivação. O projeto civilizatório da modernidade de que fala Rouanet (1993) era promissor e à escola era atribuída grande responsabilidade para sua realização. Eram três os ingredientes conceptuais básicos desse projeto: a universalidade, a individualidade e a autonomia. Diz Rouanet:

A universalidade significa que ele visa todos os seres humanos, independentemente de barreiras nacionais, étnicas ou culturais. A individualidade significa que esses seres humanos são considerados como pessoas concretas e não como integrantes de uma coletividade e que se atribui valor ético positivo à sua crescente individualização. A autonomia significa que esses seres humanos individualizados são aptos a pensarem por si mesmos, sem a tutela da religião ou da ideologia, a agirem no espaço público e a adquirirem pelo seu trabalho os bens e serviços necessários à sobrevivência material (ROUANET, 1993, p. 9).

O diagnóstico de Rouanet (1993) é que esse projeto não realizou sua promessa e "faz água por todas as juntas" (p. 9). A universalidade tinha sua expressão máxima no art. $1^{\circ}$ da Declaração dos Direitos do Homem e do Cidadão, segundo a qual "Os homens nascem e permanecem livres e iguais em direitos". Não é necessária muita discussão para ficar claro que liberdade e igualdade ainda figuram como elevados ideais cuja realização exige árdua luta por conquista. Segundo Rouanet (1993), a proliferação de particularismos nacionais, culturais, raciais ou religiosos evidencia a distância entre esses ideais e a realidade concreta dos fatos. 
A individualidade, diz ele, um dos elementos constitutivos da modernidade, expressão mais elevada da afirmação do indivíduo face à coletividade, "submerge cada vez mais no anonimato do conformismo e da sociedade de consumo" (ROUANET, 1993, p. 9). Se a individualidade se refere à liberação dos indivíduos face às estruturas que os prendiam aos domínios do coletivo, o individualismo se revela uma grave doença que faz com que cada um dê as costas aos outros, desde as relações mais domésticas e privadas até aquelas em que se espera de todos uma cooperação para o bem público.

Quanto à autonomia, Rouanet (1993) apontava para ela três dimensões. A autonomia intelectual, a autonomia política e a autonomia econômica. "A autonomia intelectual", diz ele, "estava no cerne do projeto civilizatório da Ilustração. O objetivo básico era libertar a razão do preconceito, isto é, da opinião sem julgamento" (p. 16). Kant é o seu grande artífice, ao propor que o esclarecimento é a capacidade de os homens tornarem-se senhores de si mesmos. Pelo bom uso da razão, deixariam o estado de menoridade intelectual a que tinham sido submetidos por milênios e alcançariam, por seu próprio esforço, a sua maioridade. Esse ideal trazia a expectativa de que a escola seria o lugar da sua realização. Se a escola realizou ou não esse ideal é questão abordada em amplos debates acadêmicos desde então.

A autonomia política dizia respeito à liberdade de ação do cidadão no espaço público. Seja na vertente liberal, em que essa liberdade era a garantia de que o cidadão estaria livre da ação arbitrária do Estado, ou na vertente democrática, em que o cidadão era livre para constituir o próprio Estado, a autonomia política trazia para o espaço do debate e da luta política a ideia de que os homens estabelecem contratos sociais para tornar menos árdua a vida em sociedade. A maior expressão desse contrato é o voto e o sufrágio universal é um dos maiores indicadores do grau de democracia de uma sociedade. Tanto o elevado grau de abstenção onde o voto é facultativo quanto o elevado índice de insatisfação dos eleitores com seus políticos, nos diversos cantos do mundo, são indicadores de que o projeto ainda está longe de se realizar.

A autonomia econômica trazia como característica básica a ideia de que os homens deveriam ser livres para produzir as condições materiais de existência e que somente o trabalho livre permitiria a eles essa condição. É claro que, visto de longe, esse ideal certamente contribuiu para alavancar lutas contra a servidão e a escravidão, mas basta uma rápida leitura dos jornais dos nossos dias para se perceber que o desemprego e o subemprego deixam muito distante dessa autonomia grande parte dos trabalhadores em diversas partes do mundo.

Esses ingredientes conceptuais orientaram, efetivamente, lutas históricas por transformação social e pela efetivação do projeto, uma vez que é próprio da modernidade ocidental entender o mundo como construção humana e não como 
desígnio divino. O entendimento de que o homem é sujeito da história encontrou eco em diversas formulações filosóficas, e o que foi transposto para o terreno da luta política teve efetivas repercussões em todas as dimensões da vida social, econômica, política e cultural. A Era das Revoluções (HOBSBAWM, 1982) e A Era dos Direitos (BOBBIO, 2004) são dois dentre muitos títulos que tratam dessas grandes transformações que fundaram o mundo moderno efetivamente em novas bases.

Dentre todas as promessas que emergiram desse contexto revolucionário, nenhuma se equipara em popularidade com aquela que dizia ser a educação um direito do cidadão e um dever do Estado. A partir do final do século XVIII, ampliou-se e difundiu-se esse ideal, que foi amplamente correspondido com a constituição de grandes sistemas nacionais de ensino, o que implicava construir rede física para abrigar os crescentes públicos escolares, elaborar os currículos organizadores dos percursos escolares, debater os modos mais apropriados para ensinar a todos esses públicos os conteúdos estabelecidos, fazer campanhas para que todas as crianças fossem mandadas à escola (primeiro por direito, depois por obrigação) e, claro, formar os professores e professoras que, em número crescente, esse sistema demandaria.

Essa escola deveria ensinar e instruir, mas ela deveria também educar, pois começou a ser considerada um lugar importante aonde todos não apenas deveriam ir para aprender a ler, escrever e contar, mas, sobretudo, para formar uma nova sensibilidade relativamente a esse mundo novo da vida moderna. Dentre todos os ingredientes conceptuais do projeto civilizatório da modernidade, aquele que mais se ligou à escola é o da autonomia intelectual. Nas palavras do próprio Rouanet (1993), a educação e ciência tinham importância crucial, pois eram as únicas formas de "imunizar o espírito humano contra as investidas do obscurantismo" e substituir o "dogma pelo saber, ou, para usar metáforas da época, dissipar com a luz da verdade as quimeras e fantasias da superstição" (p. 16).

Claro está que a constituição de sistemas de ensino variou de país para país e nem sempre o processo aconteceu sem percalços dentro das fronteiras de um mesmo território. Mas um olhar panorâmico sobre os processos de escolarização nos permite apontar, mesmo que apenas para efeito didático, algumas características básicas desse processo: 1) um acentuado processo de escolarização das sociedades, tanto em termos de expansão das redes de ensino quanto na extensão do atendimento aos públicos de ensino superior e aos da educação infantil; 2) uma forte correlação entre acesso a diplomas de graduação/pós-graduação e ocupação de postos mais elevados na hierarquia ocupacional, ainda que nem todos os titulados encontrem emprego nesses postos mais elevados; 3) elevada variação dessa correspondência em consonância com os momentos 
de expansão/retração da economia, o que indica, segundo Wright Mills, que "A educação [escolar] atuará como instrumento de obtenção do sucesso somente até quando as necessidades ocupacionais de uma sociedade o exijam" (MILLS, 1987, p. 278); e 4) perda da centralidade da escola como veículo de difusão do conhecimento sistematizado e, por extensão, perda da autoridade do professor como guardião desse conhecimento.

A despeito desse acentuado processo de escolarização, que se estendeu a todas as sociedades, a ponto de se configurar como um dos seus importantes indicadores de modernidade, a crise da escola começou a ser percebida desde quando os sistemas de ensino começaram a ser constituídos. Escrevendo sobre o ensino secundário francês, no final do século XIX, o sociólogo Émile Durkheim foi enfático ao cravar essa crise no cerne da estrutura social, ainda que a França do seu tempo estivesse colhendo os frutos da consolidação da Terceira República e vivendo o entusiasmo da belle époque. Segundo Durkheim, em registro que nos soa muito familiar em nossos dias:

Costuma-se fazer queixas das variações por demais freqüentes que ocorreram nos programas, nos últimos vinte anos, e culpa-se ocasionalmente essas mudanças por demais repetidas pela crise atualmente vivida pelo ensino secundário. Vê-se que essa instabilidade não data de ontem; que não é imputável a tais personalidades ou a tais circunstâncias particulares, mas sim que configura um estado crônico, que dura há um século, e depende evidentemente de causas impessoais. Longe de ser a causa do mal, é seu efeito e indício exterior; revela-o mais do que o produz. [...] Acredita-se que, para restabelecer nosso ensino secundário em bases sólidas, bastariam algumas felizes mudanças de detalhe, bastaria encontrar uma melhor dosagem das disciplinas ensinadas, aumentar a parte das letras ou das ciências, ou equilibrá-las engenhosamente, quando o necessário, na verdade, é uma mudança de espírito e orientação (DURKHEIM, 1995, p. 287-288).

Se deslocarmos nossa atenção para a mesma França, 80 anos depois de Durkheim, vamos encontrar em Jean-Claude Forquin uma leitura bastante semelhante acerca da perda da centralidade da escola e, portanto, seu mergulho na crise contemporânea. Segundo ele, "ninguém pode ensinar verdadeiramente se não ensina alguma coisa que seja verdadeira ou válida a seus próprios olhos" (FORQUIN, 1993, p. 9). O problema é que o clima de agitação cultural e a grande transformação midiática que marcaram o mundo ocidental a partir dos anos 1960 retiraram da escola o locus da aprendizagem e solaparam as bases 
sobre as quais se sustentavam os professores para levar adiante o ofício da docência. Foi essa quebra brusca tanto da instituição como locus fundamental da produção e difusão do conhecimento moderno quanto do profissional que ali atuava como seu principal agente que instaurou essa crise que se arrasta até nossos dias. Ainda que a crise da educação escolar não tenha se iniciado nessa época, como testemunha o registro de Durkheim (1995), é a partir daí que uma espécie de consciência pública dela passou a incomodar sobremaneira os profissionais do ensino e seus estudiosos. Diz ele:

Essa crise é demonstrada, em particular, pela instabilidade dos programas e cursos escolares constatada atualmente por toda parte. Não se sabe mais o que verdadeiramente merece ser ensinado a título de estudos gerais: o círculo dos saberes formadores, aquilo que os Gregos chamavam "enkuklios paidéia", perdeu seu centro e seu equilibrio; a cultura geral perdeu sua forma e sua substância. Os anos 70 fizeram triunfar um "discurso de deslegitimação" poderosamente articulado em torno de certas contribuições recentes das ciências sociais. $\mathrm{O}$ "discurso de restauração" que se esboça nos anos 80 fica muito freqüentemente confinado ao estreito âmbito do ressentimento. De fato, por toda parte, é o instrumentalismo estreito que reina, o discurso da adaptação e da utilidade momentânea, enquanto que as questões fundamentais, as que dizem respeito à justificação cultural da escola, são sufocadas ou ignoradas (FORQUIN, 1993, p. 10).

Conforme abordado em outro texto (SOUZA, 2013), essa crise instaurada no fazer pedagógico pode ser atribuída a vários fatores, mas podemos destacar pelo menos três deles como os mais relevantes. O primeiro fator aparece na citação acima e pode ser creditado ao próprio exercício da crítica (krísis) produzida pelas ciências sociais, sobretudo quando elas tomaram a educação como seu objeto privilegiado de análise. Em outras palavras, leia-se "paradigma da reprodução" e seu efeito de "deslegitimação" da autoridade pedagógica. Como se sabe, o "paradigma da reprodução" foi constituído por um conjunto de teorias sociológicas da educação que se desenvolveram, principalmente na França, a partir dos anos 1960, e que traziam uma nova explicação sobre a relação entre escola e sociedade. Ele indica que a escola funciona mais como mecanismo de reprodução da realidade social que de produção de novas relações sociais, e exerceu enorme influência na crítica às instituições escolares. Nas décadas de 1960 e 1970, uma grande quantidade de estudos sobre a escola passou a 
denunciá-la como instrumento de reprodução social, o que inverteu radicalmente a expectativa que se tinha dela. A promessa cedeu lugar ao desencanto. Louis Althusser (1969) denunciou a escola como espaço de reprodução da ideologia dominante. Pierre Bourdieu e Claude Passeron (1992) denunciaram-na como espaço de reprodução da cultura dominante. Christian Baudelot e Roger Establet (1972) viram nela os espaços de reprodução das relações de classe do capitalismo. Basta ler o livro de Pierre Bourdieu e Claude Passeron (1992) que deu nome ao paradigma para se ter certeza disso.

Um segundo fator, talvez como decorrência desse primeiro e também apontado na citação, foi a desestabilização trazida pela crítica severa de que foram alvo a escola e os profissionais do ensino. Ao deslegitimar os saberes escolares sob o argumento de que eles constituíam um arbitrário cultural, e as práticas pedagógicas sob o argumento de que elas legitimavam esse arbitrário, os professores foram jogados no limbo da indefinição curricular e da insegurança relativa ao quê e ao como ensinar. A ampliação do debate que se seguiu até o final do século e aos nossos dias, a despeito do repetido jargão que associa educação à transformação, em vez de apontar novas possibilidades pedagógicas e criar novas referências para o trabalho docente, parece ter sido sufocada no criticismo e esgotado a capacidade de criar algo efetivamente novo e estabelecer alguma segurança aos professores em seu ofício.

Um terceiro fator, talvez o mais importante a ser destacado, foi a mudança do perfil da escola, com a entrada de públicos que, até então, não eram parte dela, ou que, apesar de ter tentado anteriormente fazer parte dela, eram mandados de volta para casa sem que ninguém se incomodasse com isso. Ao se realizar o desiderato da escola para todos, direito do cidadão e dever do Estado, os profissionais do ensino se viram diante de um alto preço a pagar por essa conquista. Pois, uma coisa é ter uma escola para públicos já predispostos à escolarização e na qual ficam aqueles que se adaptam aos seus rituais e sobrevivem às suas exigências. Coisa muito distinta é ter uma escola para todos, não apenas no discurso, mas numa prática cotidiana que não apenas dê conta do jogo das diferenças, mas que assegure aos desiguais as mesmas condições de percurso. Acrescente-se a essa condição discente - alunos que vêm não apenas de lugares diferentes, mas, também, desiguais - uma condição docente cada vez mais atravessada pela precarização do trabalho e desvalorização do ofício, num cenário em que professores e opinião pública internalizaram como habitus a consciência de que todos devem ser escolarizados, e teremos pelo menos parte da explicação do porquê a crise atual na educação tem como uma de suas decorrências o adoecimento dos professores ou o elevado grau de absenteísmo ao trabalho (DIAS, 2012). 


\section{As licenciaturas}

Disso decorre, portanto, que há fortes evidências, nos dias atuais, de que a profissão docente vive uma crise sem precedentes na história do nosso ensino, uma crise estrutural, conforme foi dito anteriormente. A despeito da grande diversidade de condições da oferta e demanda por escolarização, tanto no que se refere à condição docente quanto à condição discente, produto da diferenciação sociocultural e das desigualdades socioeconômicas, essa crise atravessa a estrutura da pirâmide escolar de alto a baixo, não apenas no Brasil, mas em várias partes do mundo.

Ela combina ingredientes de natureza muito diversa, mas o elemento-chave da sua explicação é o baixo valor do diploma de professor, sobretudo na educação básica, tanto no mercado de bens econômicos (salário) quanto no mercado de bens simbólicos (prestígio). Esse baixo valor do diploma expressa uma terrível contradição: quanto mais expandimos a oferta do ensino escolar, maior se revela nossa dificuldade de formar professores para atendê-la. Quanto mais escolarizada se torna nossa sociedade, maior é a sensação de que a escola não corresponde ao que esperamos dela no nosso tempo.

Pode-se dizer, então, que estamos pagando o preço caro por uma conquista. Desde o século XVIII, na Europa, e pelo menos desde o final do século XIX, no Brasil, reivindica-se educação como direito do cidadão e dever do Estado. Como resultado dessa reivindicação, todos - ou quase todos - vieram para a escola. Vieram os filhos dos camponeses, os dos moradores das periferias urbanas, os indígenas, os deficientes físicos e, inclusive, um público altamente refratário ao que a escola espera dele e deseja para ele. Vieram todos por direito, como resultado de lutas históricas pela sua inclusão nos sistemas de ensino. Mas, como não há milagres em matéria de educação e ensino, isso também exigiria formar em quantidade e qualidade os professores que dariam conta dessa tarefa em condições que correspondessem à elevada expectativa criada por essa ampliação do atendimento escolar.

Ao se encerrar o século XX, o Brasil comemorava a universalização do ensino fundamental e atualmente trabalhamos arduamente para universalizar, até 2016, a educação infantil e o ensino médio, cujo atendimento está na casa dos 50\%, variável entre as regiões. Não bastasse a escassez de professores para a demanda atual, que o Ministério Educação (MEC) já contabiliza na casa dos 250 mil, sobretudo para o ensino das ciências da natureza, universalizar a educação básica implica a necessidade de formar mais e bem os professores para realizar a tarefa. Essa legítima proposta do Plano Nacional de Educação (PNE) 
esbarra, contudo, em problemas cuja gravidade nos deixa poucas expectativas para sua realização. Mais uma vez, o projeto pode revelar-se uma promessa muito difícil de ser cumprida.

Um desses problemas é a baixa atratividade da carreira docente, com recrutamento dos estudantes dos cursos de licenciatura justamente entre aqueles de escolarização básica mais precária. Isso já evidencia que o acesso ao ensino superior não se dá do mesmo modo para os membros de todas as classes sociais e que a maioria dentre aqueles que estão rompendo as barreiras econômicas e realizando o sonho de chegar à universidade, o fazem pela via dos cursos cujo valor do diploma é bem menor. Indicador preocupante dessa baixa atratividade está expresso na relação candidato/vaga dos últimos 14 vestibulares da Universidade Federal de Minas Gerais (UFMG) (2000-2013), o que parece estar longe de ser uma situação exclusiva desta Universidade. Em 2000, dos 17 cursos mais concorridos, seis formavam professores. Nos vestibulares 2012 e 2013, não houve um único curso de licenciatura entre os 15 mais concorridos.

Mantida essa tendência, em três ou cinco anos não teremos candidatos aos cursos de licenciatura. Cursos como Ciências Biológicas, Educação Física, Geografia, História, Letras, Matemática e Pedagogia, que eram disputados numa correlação de 12 a 30 candidatos por vaga, há dez anos, para 2012 contaram, respectivamente, com 3,$5 ; 2,1 ; 1,6 ; 4,8 ; 1,4 ; 2,9$; e 3,0 candidatos para cada vaga. Situação semelhante aconteceu no vestibular 2013, com queda ainda mais acentuada em alguns desses cursos. Mesmo considerando que houve aumento do número de vagas em alguns deles, redução da concorrência em outros cursos que não os de licenciatura e que caiu de 18 para 9 a média geral da relação candidato/vaga na Universidade, a generalizada queda da concorrência nos cursos de licenciatura é forte indício do crescente desinteresse pela docência atualmente. Além dessa diminuição da procura por seus cursos de licenciatura, a despeito do aumento do número de vagas, a UFMG forma hoje metade dos professores que formava dez anos atrás.

Mas isso é apenas parte do problema. Um segundo elemento a ser considerado é o elevado índice de desistência da profissão. Grande número dos que se formam professores não terão as salas de aula como destino ocupacional. Estudo recente sobre alunos que cursaram História entre 1998 e 2001 aponta que, dos 45 que entraram (44 vestibular +1 obtenção de novo título), 38 se formaram; desses, 7 estavam na sala de aula na ocasião da pesquisa, sendo que 4 revelaram que estavam em vias de abandoná-la, ou seja, somente três pretendiam continuar atuando como professor da educação básica (AMORIM, 2012).

A UFMG fez elevado investimento, nas duas últimas décadas, criando cursos exclusivamente de licenciatura, em que a escolha precede o vestibular. Grande parte dos alunos desses cursos diz explicitamente que a sala de aula 
não é a sua opção. E um dos motivos mais apontados é a informação sobre o elevado índice de abandono da profissão, isto é, professores experientes que se afastam por adoecimento ou por não suportarem mais ser vítimas de violência física e/ou simbólica no cotidiano da sala de aula.

Internamente, a Universidade tem enfrentado o problema com ações como o Programa Institucional de Bolsas de Iniciação à Docência (PIBID), que concede bolsas de estudos e realiza um diferenciado trabalho de formação para alunos dos cursos de licenciatura. Trata-se de projeto inovador e que tenta garantir condições mais adequadas de percurso escolar desses estudantes. Contudo, se não forem modificadas as condições gerais da docência, para fazer dela uma carreira atrativa, há fortes indícios de que não teremos professores para atuar na universalização da educação básica, conforme prevê o PNE.

\section{A formação inicial e continuada dos docentes}

A formação docente tem se constituído num dos maiores desafios à educação, uma vez que o que entendemos por desenvolvimento profissional não é algo que se esgota com a formação inicial, por mais consistente que seja, e nem se conquista com os tradicionais cursos de fim de semana realizados em nome da formação continuada. Segundo o Parecer no 9, de 2001, do Conselho Nacional de Educação/Conselho Pleno (CNE/CP), que fundamentou a Resolução $\mathrm{CNE} / \mathrm{CP} \mathrm{n}^{\circ} 1$, de 2002, apesar dos significativos avanços relativamente ao acesso à Educação Básica em nosso país, há sérios problemas a serem superados na aprendizagem dos alunos no sentindo de permitir-lhes um acesso real ao conhecimento sistematizado, ao acervo cultural acumulado pela humanidade e às condições objetivas que tornam possível uma educação verdadeiramente inclusiva. E mesmo se considerando que este não é o único fator importante para o bom desempenho dos estudantes, uma boa qualificação dos professores pode ser fator decisivo quando o assunto é qualidade da educação.

Uma leitura atenta dos pareceres do CNE e das respectivas Resoluções que eles fundamentaram ao estabelecer as diretrizes dos cursos de licenciatura, sua duração e carga horária, nos permite ver que são bastante consideráveis os avanços trazidos pela nova regulação dos cursos de formação de professores (SOUZA, 2007; 2013): o caráter democrático da sua elaboração, que resultou de amplo debate com representantes de grande número de entidades ligadas à educação escolar; a reivindicação da profissionalização da docência, vista como algo que exige mais do que a posse de um dom ou a entrega pessoal a uma 
vocação; o estabelecimento de autonomia do percurso de formação docente, visando superar a visão da licenciatura como apêndice do bacharelado; nova concepção de educação básica, extensiva a toda a população de zero a 17 anos; ampliação da dimensão prática da formação, com grande aumento da carga horária de estágios; e a busca da formação das competências, visando superar "a improvisação, o amadorismo, a mediocridade", para usar as palavras de Iria Brzezinski (1998, p. 166).

Esse esforço, contudo, de melhor organizar internamente os cursos de licenciatura não nos pode fazer esquecer que não se mudam práticas cristalizadas no tempo apenas com pareceres e resoluções e que os fatores internos às universidades não podem ser lidos fora do contexto social no qual cada uma delas está inserida. Não basta, pois, uma organização curricular que supere o famoso $3+1$, se as práticas cotidianas dos professores formadores estabelecem uma hierarquia entre bacharelado e licenciatura, em que a formação pedagógica, quando não é vista como inteiramente desnecessária, é apenas tolerada como um verniz cultural, já que o essencial da formação, segundo esses professores, é o domínio dos conteúdos específicos de cada área.

Ora, é claro que ninguém pode ensinar o que não sabe e é de se esperar que os futuros professores dominem muito bem esses conteúdos específicos de cada área. Mas se espera desses mesmos professores que, além desse domínio, eles conheçam também os fundamentos do conhecimento, os motivos pelos quais se ensina e os meios através dos quais o processo ensino-aprendizagem deve ser organizado com vistas a alcançar maior eficácia. Se, conforme citado anteriormente, para Jean-Claude Forquin "ninguém pode ensinar verdadeiramente se não ensina alguma coisa que seja verdadeira ou válida a seus próprios olhos" (1993, p. 9), ninguém pode ensinar verdadeiramente se não consegue ajustar os conteúdos do ensino a cada etapa do processo de escolarização. E se isso não é um dado da natureza, é preciso que seja aprendido pelos futuros professores desde os cursos de formação inicial.

Além da necessidade de reconhecer a especificidade da formação docente e garantir aos cursos de licenciatura um projeto pedagógico específico, percurso independente e titulação definida como graduação plena, é preciso tirar proveito da ampliação da carga horária de prática e estágio, a fim de garantir ao futuro profissional do ensino maior capacidade de fazer do conhecimento acadêmico um instrumento adequado para enfrentar situações concretas do cotidiano da sala de aula. Mas o modo como a carga horária geral dos cursos de licenciatura (2.800 horas) e, particularmente, da carga horária de prática e estágio (800 horas) foi incorporada aos currículos ainda parece ser uma incógnita. Tão acalorados foram os embates a esse respeito, que o CNE chegou a aprovar, em 2006, um parecer (Parecer CNE/CP nº 2, de 2006, não traduzido em nova Resolução) pelo qual 
seria revogada a Resolução n ${ }^{\circ}$ 2, de 2002, e estabelecida menor carga horária de estágio. Implicação concreta desse debate foi a Resolução $\mathrm{CNE} / \mathrm{CP}^{\circ}{ }^{\circ} 1$, de 2006, que estabeleceu as diretrizes dos cursos de Pedagogia, que também são de licenciatura, com estágio de 300 horas.

É antiga essa discussão que aponta para a necessidade de garantir uma formação assentada numa relação dialética entre teoria e prática, condição necessária ao exercício de qualquer profissão que tenha lugar em um mundo caracterizado cada vez mais por vertiginoso processo de mudanças em todas as esferas da realidade. Se isso constitui um apontamento inconteste para qualquer profissão moderna, mais incontestável ainda se torna quando o que está em jogo é a formação dos profissionais que estarão à frente da formação de todos os outros. Mas a precariedade que caracteriza a formação inicial dos docentes em nossos dias (GATTI; BARRETO, 2009) deixa pouca margem a outro diagnóstico senão o de uma crise sem precedentes, uma combinação dramática de elementos externos (enorme distância entre o ideal pedagógico que diz valorizar a educação e a realidade concreta da escola; baixo valor do diploma de professor; ausência de um ethos universal de valorização da educação e da escola) e internos à escola (combinação de precariedade da formação básica com precariedade do percurso escolar; elevado índice de desistência e abandono da profissão; aumento da carga horária mínima de prática e estágio não se traduz em melhoria da qualidade da oferta do curso; arranjos precários para incorporar o aumento de carga horária sem inflacionar os encargos docentes; oferta predominante dos cursos de licenciatura no turno noturno), dentre muitos outros (SOUZA, 2013).

Notável, também, no rol dos problemas que expressam a crise das licenciaturas é a sua proliferação na rede privada de ensino, exatamente por serem cursos mais baratos e de mais fácil oferta. Na última década, as instituições de ensino superior, que são da ordem $90 \%$ do total, ofereceram em torno de $70 \%$ das matrículas no ensino superior, o que mostra que a formação de professores está maciçamente concentrada na iniciativa privada. Mas essa facilitação da oferta, contudo, parece ter manifestado sinais de esgotamento, dado o expressivo número de vagas não preenchidas, conforme amplamente noticiado cada vez que o Instituto Nacional de estudos e Pesquisas Educacionais Anísio Teixeira (INEP) divulga o Censo Educacional.

Mesmo tomada como relevante e assumida de fato como consistente, uma graduação plena não permite mais que uma formação inicial. Já vem de longa data o entendimento de que o exercício da docência requer uma formação continuada, tanto como direito do professor à ampliação do seu conhecimento quanto como direito do aluno a ter um professor constantemente atualizado. Mas ao confrontar a demanda por formação continuada com as condições da docência, podemos observar claramente que, excetuando-se os programas de qualificação 
dos professores das instituições públicas de ensino superior, ao realizar doutorado e pós-doutorado, ou são poucas as possibilidades da sua realização pelos docentes da educação básica ou são realizadas de modo muito precário. Ainda que muitos tirem bom proveito, por investimento e esforço próprios, ao realizar um curso de fim de semana ou de férias, não parece ser necessário muito argumento para deixar claro que submeter os professores a cursos de qualificação nessas ocasiões é subtrair deles o sagrado direito ao descanso.

A formação continuada deve, pois, ser entendida como desenvolvimento profissional, uma possibilidade de proporcionar novas reflexões sobre a ação e novos meios para desenvolver e aprimorar o trabalho pedagógico. Ela deve ser vista como um processo de construção permanente do conhecimento, que toma a formação inicial como ponto de partida, a formatura em graduação plena apenas como a conclusão de um percurso e a busca do aperfeiçoamento intelectual como um processo mais amplo de humanização, uma produção de si mesmo na interação com o outro.

A formação continuada, contudo, confronta questões que não existem ou são negligenciadas nos processos de formação inicial. Jovens estudantes de licenciatura não conhecem da escola básica quase nada além do que apreenderam dela como estudantes que foram outrora. Professores, pelo contrário, constroem saberes na prática pedagógica cotidiana que, mesmo de forma intuitiva e pouco sistemática, compõem o seu repertório de conhecimento sobre ensino, educação e escola. A formação continuada precisa considerar esses saberes, uma vez que não há necessariamente uma coincidência entre o conhecimento que a academia produz da escola básica e o modo concreto do seu funcionamento. Quando François Dubet se propôs a ser professor de história e geografia em um colégio da periferia de Bordeaux, na França, seu propósito foi vivenciar, diretamente como professor, os dilemas da escola francesa contemporânea que ele conhecia apenas por suas pesquisas sobre a juventude marginalizada na França. Ainda que relevantes, cada qual à sua maneira, são experiências tão distintas que entre o sociólogo e o professor pode haver barreiras instransponíveis (PERALVA; SPOSITO, 1997).

Diferentes autores insistem em afirmar que, numa atividade de formação continuada, deve-se levar em consideração não apenas os conhecimentos próprios de cada campo como também os saberes que professores adquirem na sua experiência, fruto de sua vivência e enfrentamento de situações cotidianas da escola (NÓVOA, 1991; TARDIF, 2002). Para Antonio Nóvoa (1991), não há possibilidade de produzir um conhecimento pedagógico para além dos professores, ou seja, que ignore as dimensões pessoais e profissionais do trabalho docente. $\mathrm{E}$ acrescenta que a profissionalização docente é conquistada a partir desse saber experiencial. É preciso, portanto, conhecer o sujeito professor, considerando 
sua vida e seus projetos, suas crenças, valores, atitudes e ideais, pois, para o autor, esses fatores influenciam o modo como o professor organiza as suas aulas, movimenta-se na sala, dirige-se aos alunos e usa os instrumentos pedagógicos.

Maurice Tardif (2002) afirma também que esses saberes não constroem um conjunto de conhecimento unificado em torno de uma disciplina, de uma tecnologia ou de uma concepção de ensino, pois são variados, ecléticos, sincréticos. Para ele, dificilmente, os professores têm uma teoria, uma concepção única que utiliza em sua prática. Eles usam muitas teorias pessoais (tácitas, implícitas), concepções e técnicas conforme a necessidade e o contexto específico vivenciado. Os docentes mantêm uma relação com os saberes de acordo com os objetivos que pretendem atingir. $\mathrm{O}$ saber dos professores é o saber deles e está relacionado à pessoa e à identidade deles, à sua experiência de vida e à sua história profissional, às suas relações com os alunos em sala de aula e aos outros atores escolares na escola. Não considerar isso pode pôr a perder todo o esforço bem intencionado de levar adiante políticas de formação continuada de professores.

Mas mesmo considerando legítimos esses saberes, não se encerra neles, nem de longe, o essencial daquilo que os professores precisam dominar para o adequado exercício do seu ofício. Mesmo que fosse possível, em um curso de formação inicial, garantir o essencial daquilo que caberá ao futuro professor ensinar, ainda assim, ele estará exercendo sua profissão em um mundo em constante transformação. Não apenas mudam os conteúdos que cada campo de conhecimento considera essenciais, o que supõe necessidade de atualização constante do professor; há as novas demandas sociais, as questões próprias de cada tempo. Uma das questões próprias do nosso tempo é a que reivindica da escola formar nos públicos escolares uma sensibilidade relativamente às diferenças.

Pensar, pois, a formação docente no contexto da crescente luta da educação pelo reconhecimento da diversidade, é questão fundamental. Se não se trata de questão acadêmica nova, sua visibilidade pública não remonta talvez a mais que uma ou duas décadas. Ora, reside exatamente aí a dificuldade de se fazer da escola o lugar das respostas imediatas que, de modo geral, se quer da educação. Grande parte dos professores que atuam na escola básica teve sua formação inicial em outros tempos, quando as sensibilidades eram outras e não necessariamente tiveram a oportunidade de se submeter a cursos de formação continuada para tomar ciência dessas novas demandas do tempo presente e, mesmo que tenham se submetido, não necessariamente foram tocados por essas questões. A não correspondência entre essas demandas, tomadas como novos projetos para a educação, e aquilo que a escola efetivamente faz pode nos dar a sensação de que essa escola vive uma terrível crise. Estar em crise é não dar conta de realizar as promessas, que são renovadas a cada dia, expressão mesmo de uma dinâmica social que não cessa de nos fazer confrontar, a cada dia, novas questões. 


\section{REFERÊNCIAS}

ALTHUSSER, L. Ideologia e aparelhos ideológicos de estado. Porto: Presença, 1969.

AMORIM, M. A. Histórias de jovens profissionais da História: trajetórias de egressos do curso de História da FAFICH/UFMG (1998/01). In: PL912. LabepeH promove diálogos com Marina Alves Amorim (out.2012) - parte 1.10 nov. 2012. Disponível em: <http:// www.youtube.com/watch?v=p8G0LfK8PDw>. Acesso em: 11/10/2013.

BAUDELOT, C; ESTABLET, R. L'école capitaliste en France. Paris: Maspero, 1972.

BOBBIO, N. A era dos direitos. São Paulo: Campus, 2004.

BOURDIEU, P.; PASSERON, J. C. A reprodução: elementos para uma teoria do sistema de ensino. $3^{\text {a }}$ ed. Rio de Janeiro: Francisco Alves, 1992.

BRASIL. Ministério da Educação. Conselho Nacional da Educação. Conselho Pleno. Parecer $n^{\circ}$ 9, de 8 de maio de 2001. Diretrizes Curriculares Nacionais para a Formação de Professores da Educação Básica, em nível superior, curso de licenciatura, de graduação plena. Diário Oficial da União, Brasília, DF, 18 jan. 2002.

. Ministério da Educação. Conselho Nacional da Educação. Conselho Pleno. Resolução $n^{\circ} 1$, de 18 de fevereiro de 2002. Institui Diretrizes Curriculares Nacionais para a Formação de Professores da Educação Básica, em nível superior, curso de licenciatura, de graduação plena. Diário Oficial da União, Brasília, DF, 4 mar. 2002a.

. Ministério da Educação. Conselho Nacional da Educação. Conselho Pleno. Resolução $n^{\circ} 2$, de 19 de fevereiro de 2002. Institui a duração e a carga horária de licenciatura, de graduação plena, de formação de professores da Educação Básica em nível superior. Diário Oficial da União, Brasília, DF, 4 mar. 2002b.

. Ministério da Educação. Conselho Nacional da Educação. Conselho Pleno. Parecer $n^{\circ} 2$, de 31 de janeiro de 2006. Recurso contra a decisão do Parecer CNE/CES n ${ }^{\circ}$ $6 / 2005$, referente ao credenciamento para oferta de cursos de especialização, em regime presencial, na área de Economia. Diário Oficial da União, Brasília, DF, 19 maio 2006a.

. Ministério da Educação. Conselho Nacional da Educação. Conselho Pleno. Resolução no 1 , de 15 de maio de 2006. Institui Diretrizes Curriculares Nacionais para o Curso de Graduação em Pedagogia, licenciatura. Diário Oficial da União, Brasília, DF, 16 maio 2006b.

BRUNKHOST, H. Crise. In: BOTTOMORE, T.; OUTHWAITE, W. (Orgs.) Dicionário do pensamento social do século XX. Rio de Janeiro: Zahar, 1996. p. 165-160.

BRZEZINSKI, I. Notas sobre o currículo na formação de professores: teoria e prática. In: SERBINO, R. V. et al. Formação de professores. São Paulo: UNESP, 1998. p. 161-174.

BOURDIEU, P.; PASSERON, J. C. A reprodução: elementos para uma teoria do sistema de ensino. 3. ed. Rio de Janeiro: Francisco Alves, 1992. 
CUNHA, A. G. Dicionário etimológico da língua portuguesa. 4. ed. Rio de Janeiro: Lexikon, 2010.

DIAS, M. S. A. Absenteísmo docente: manifestação do fenômeno na Rede Municipal de Belo Horizonte (2009-2010). Dissertação (Mestrado em Educação) - Faculdade de Educação, Universidade Federal de Minas Gerais, Belo Horizonte, 2012.

DECLARAÇÃO dos direitos do homem e do cidadão. Revista da $O A B / R J$. N. 19, Rio de Janeiro: OAB, 1992.

DURKHEIM, É. A evolução pedagógica. Porto Alegre: Artes Médicas, 1995.

FERREIRA, A. B. de H. Novo dicionário da língua portuguesa. Rio de Janeiro: Nova Fronteira, 1986.

FORQUIN, J. Escola e cultura: as bases sociais e epistemológicas do conhecimento escolar. Porto Alegre: Artes Médicas, 1993.

GATTI, B.; BARRETO, E. Professores do Brasil: impasses e desafios. Brasília, DF: UNESCO, 2009.

HOBSBAWM, E. A era das revoluções (1789-1848). 4. ed. Rio de Janeiro: Paz e Terra, 1982. HOUAISS, A. Dicionário Houaiss da língua portuguesa. Rio de Janeiro: Objetiva, 2001.

MILLS, C. W. Educação e classe social. In: PEREIRA, L.; FORACCHI, M. Educação e sociedade: leituras de sociologia da educação. 13. ed. São Paulo: Nacional, 1987. p. 161-180.

NÓVOA, A. Para o estudo sócio-histórico da gênese e desenvolvimento da profissão docente. Teoria \& Educação, Porto Alegre, n. 4, p. 109-139, 1991.

PERALVA, A. T.; SPOSITO, M. P. Quando o sociólogo quer saber o que é ser professor: entrevista com François Dubet. Revista Brasileira de Educação, Rio de Janeiro, n. 5-6, p. 222-231, maio/dez. 1997.

ROUANET, S. P. Iluminismo ou barbárie. In: _. Mal-estar na modernidade: ensaios. São Paulo: Companhia das Letras, 1993. p. 9-45.

SOUZA, J. V. A. de. Licenciaturas na UFMG: desafios, possibilidades e limites. In: (Org.). Formação de professores para a educação básica: dez anos da LDB. Belo Horizonte: UFMG, 2007. p. 27-44.

. Os profissionais do ensino como mediadores das culturas na escola. In:

(Org.). Formação de professores e condição docente. Belo Horizonte: UFMG, 2013. (no prelo).

TARDIF, M. Saberes docentes e formação profissional. Petrópolis: Vozes, 2002.

Texto recebido em 10 de agosto de 2013.

Texto aprovado em 11 de outubro de 2013. 